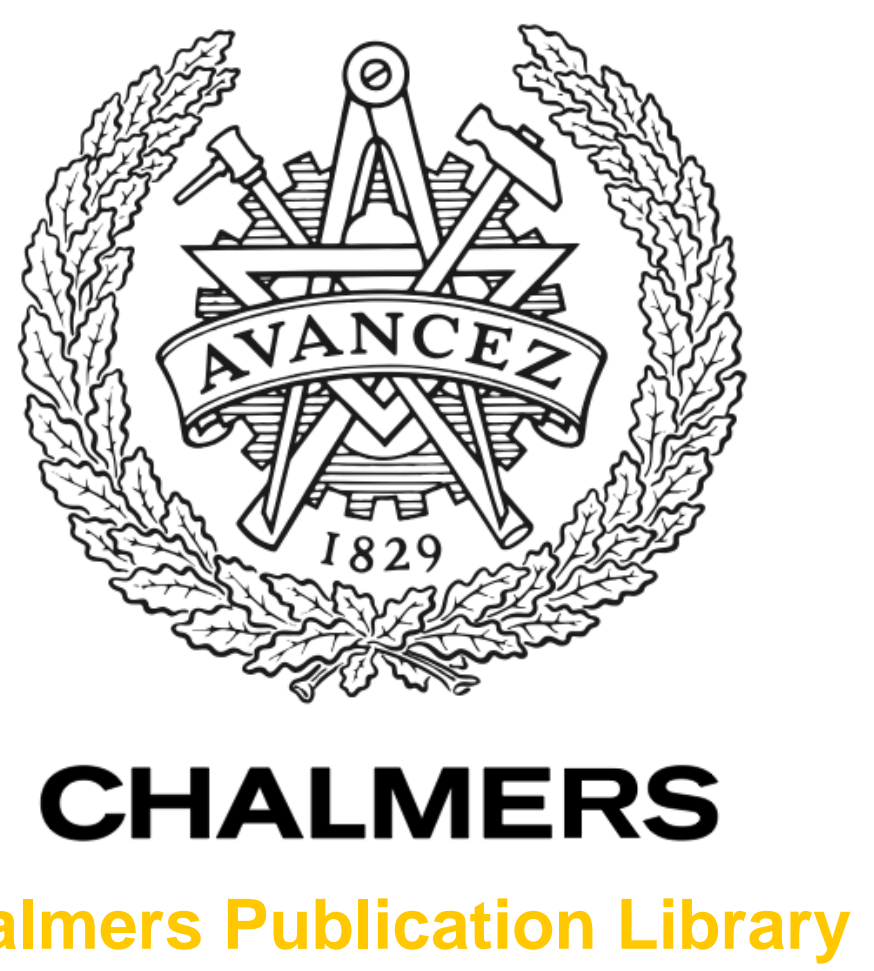

\title{
Deposits on heat transfer tubes during co-combustion of biofuels and sewage sludge
}

This document has been downloaded from Chalmers Publication Library (CPL). It is the author's version of a work that was accepted for publication in:

Fuel

Citation for the published paper:

Åmand, L. ; Leckner, B. ; Eskilsson, D. et al. (2006) "Deposits on heat transfer tubes during co-combustion of biofuels and sewage sludge". Fuel, vol. 85(10-11), pp. 1313-1322.

Downloaded from: http://publications.lib.chalmers.se/publication/20436

Notice: Changes introduced as a result of publishing processes such as copy-editing and formatting may not be reflected in this document. For a definitive version of this work, please refer to the published source. Please note that access to the published version might require a subscription. 


\title{
Deposits on heat transfer tubes during co-combustion of biofuels and sewage sludge
}

\author{
Lars-Erik Åmand $^{\mathrm{a}, *}$, Bo Leckner ${ }^{\mathrm{a}}$, David Eskilsson ${ }^{\mathrm{b}}$, Claes Tullin ${ }^{\mathrm{b}}$ \\ ${ }^{a}$ Division of Energy Conversion, Department of Energy and Environment, Chalmers University of Technology, SE-412 96 Göteborg, Sweden \\ ${ }^{\mathrm{b}}$ Department of Energy Technology, SP Swedish National Testing and Research Institute, P.O. 857, SE-501 15 Borås, Sweden
}

Received 14 November 2005; received in revised form 28 December 2005; accepted 3 January 2006

Available online 30 January 2006

\begin{abstract}
Potassium together with chlorine is the principal species that causes undesirable deposits and eventually corrosion on heat exchanger tubes in boilers fired with bio and waste fuels. It is shown here by tests in a circulating fluidized bed boiler that co-combustion of biomass with another fuel, in this case municipal sewage sludge, can remove or considerably reduce such deposits at the same time as the amount of submicron particles deceases radically. There may be at least four reasons for the beneficial impact of the additional fuel: (1) sulphur in the fuel may react with potassium, producing sulphate and gaseous hydrogen chloride which are less harmful, (2) potassium chloride may be removed by condensation on fly ash particles added with the other fuel, or (3) potassium in gaseous form may react with alumino-silicates provided by the additional fuel, and finally, (4) deposits may be mechanically removed by the increased ash flows caused by the additional fuel. In one of these ways or a combination of them, formation of deposits on tubes by potassium chloride could be avoided or alleviated.
\end{abstract}

(C) 2006 Elsevier Ltd. All rights reserved.

Keywords: Biofuel; Sewage sludge; Deposits; Corrosion; Co-combustion; Fluidized bed

\section{Introduction}

Recovery of energy from biomass and non-recyclable waste products by combustion has become important. However, these materials contain impurities that may cause problems of various kinds, not only emissions, but also deposits on heat transfer surfaces in the combustion device. The present work focuses on formation of deposits. Such deposits interfere with operation and eventually lead to corrosion or blockage of gas paths. This problem has been studied thoroughly. A few recent publications related to biofuels can be mentioned as examples [1-4]. In continuation of a recent study on combustion of demolition wastes from buildings [5], here, co-combustion of this material with sewage sludge will be investigated with the purpose of determining the effect of the combination of fuels with different properties on deposit formation. Particular attention will be paid to the particle size distribution of the fly ashes and its significance for deposits. Alkali compounds are released in gaseous form during combustion, whereas

\footnotetext{
* Corresponding author. Tel./fax: +31 7721439.

E-mail address: lars-erik.amand@me.chalmers.se (L.-E. Åmand).
}

0016-2361/\$ - see front matter (C) 2006 Elsevier Ltd. All rights reserved. doi:10.1016/j.fuel.2006.01.001 (depending on combustion temperature) most other ash constituents are released as fragments larger than a micron. The inorganic gases condense homogeneously or heterogeneously, forming submicron particles (in contrast to the ash fragments that are greater than a micron), as the temperature falls in the flue gas pass or in the vicinity of heat transfer surfaces. A thorough description of the details of these ashrelated processes has been given by Sarofim and Helble [6]. Although the description in this reference is for coal-powder combustion, most features are applicable to biomass and sludge as well. The particles formed may deposit on heat transfer surfaces through diffusion (small particles) or impaction (large particles) and deposits build up. In the present work short term tests are carried out and, hence, the initial stage of deposit formation is studied.

The tests were carried out in a circulating fluidized bed (CFB) boiler, a combustion device that is particularly suitable for co-combustion involving sludge. The results can be extended to various types of biofuel co-fired with additional fuels, fulfilling conditions that are similar to those treated here.

\section{The test programme}

In order to avoid temporal variations of fuel composition and to focus on potentially important origins of deposits on 
Table 1

Molar ratio of some fuel constituents in the test cases

\begin{tabular}{|c|c|c|c|c|c|}
\hline \multirow[t]{2}{*}{ Fuel mix, run } & \multicolumn{5}{|l|}{ Molar ratio } \\
\hline & $\overline{\mathrm{Cl} /(\mathrm{K}+\mathrm{Na})}$ & $2 \mathrm{~S} /(\mathrm{K}+\mathrm{Na})$ & $\mathrm{S} / \mathrm{Cl}$ & $\mathrm{S} /\left(\mathrm{Ca}+\mathrm{K}_{2}+\mathrm{Na}_{2}\right)$ & $(\mathrm{Al}+\mathrm{Si}) / \mathrm{Cl}$ \\
\hline WP38 & 0.2 & 0.3 & 0.9 & 0.1 & 5.5 \\
\hline WP33+MS13 & 0.1 & 1.0 & 6.1 & 0.3 & 100 \\
\hline WP56+ ZnO & 0.3 & 0.4 & 0.6 & 0.1 & 3.7 \\
\hline $\mathrm{WP} 48+\mathrm{ZnO}+\mathrm{MS} 5$ & 0.2 & 1.2 & 3.6 & 0.3 & 33.9 \\
\hline $\mathrm{WP} 47+\mathrm{ZnO}+\mathrm{MS} 9$ & 0.2 & 1.9 & 6.1 & 0.4 & 47.9 \\
\hline $\mathrm{WP} 51+\mathrm{ZnO}+\mathrm{HCl}$ & 2.0 & 0.7 & 0.2 & 0.2 & 0.8 \\
\hline $\mathrm{WP} 44+\mathrm{ZnO}+\mathrm{HCl}+\mathrm{MS} 6$ & 0.8 & 1.6 & 1.0 & 0.4 & 10.1 \\
\hline $\mathrm{WP} 43+\mathrm{ZnO}+\mathrm{HCl}+\mathrm{MS} 10$ & 0.5 & 1.7 & 1.7 & 0.4 & 15.6 \\
\hline
\end{tabular}

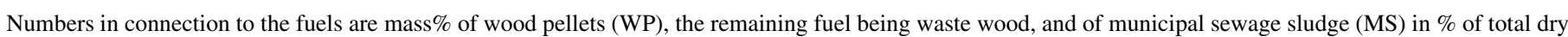
fuel mass.

heat transfer tubes, in the present test programme a substitute fuel was employed, composed of wood with additions of chlorine $(\mathrm{HCl})$ and zinc $(\mathrm{ZnO})$, the first addition to simulate a more aggressive fuel than pure wood, and the latter to simulate the impact of white coloured paint, remaining on some waste woods (such as demolition waste). The wood was a mixture of waste wood and wood pellets with quite similar properties, made to control the heat balance, and, hence, the bed temperature of the CFB boiler used for the experiments. In this way, and by adjusting the boiler, constant operation conditions were maintained during all tests, despite additions of wet co-fuel (sludge) in some of the test runs. During the tests, deposits were measured on a tube inserted horizontally into the centre of the flue-gas path, just downstream of the cyclone in the CFB boiler. The fly ash was analysed with regard to composition, size and number distributions after sampling in a position downstream of the convection section. Gas analysis was also carried out.

Three sets of tests were run according to Table 1: (a) wood without addition of $\mathrm{HCI}$ and $\mathrm{ZnO}$, alone and with some sewage sludge, (b) wood with addition of $\mathrm{ZnO}$ (corresponding to an increase in the $\mathrm{Zn}$ content of dry fuel from 6.5 to $115 \mathrm{~g} / \mathrm{kg}$ dry ash) alone and with sewage sludge, and (c) wood with addition of $\mathrm{ZnO}$ and chlorine in the form of $\mathrm{HCl}$ (corresponding to an increase of the $\mathrm{Cl}$ content of the fuel from 0.03 to $0.16 \%$ daf) again, alone and with sewage sludge. Table 1 expresses molar ratios of species according to the fuel analysis of Table 2. The data reveal that there is a deficit of sulphur in relation to fuel alkali, and there is also a deficit of chlorine unless chlorine is added. The addition of zinc is small and not important in the present context. Calcium competes with $\mathrm{K}$ and $\mathrm{Na}$ for the sulphur. The excess of sulphur, illustrated by the ratio $2 \mathrm{~S} /(\mathrm{K}+$ $\mathrm{Na}$ ), disappears when the lime in the fuel ash is taken into account. The ratio of $(\mathrm{Al}+\mathrm{Si}) /(\mathrm{K}+\mathrm{Na})$ is relevant when discussing the reactions of alkali with aluminium silicates. Sludge supply strongly increases this ratio.

The composition of the fuels is given in Table 2 . The sludge is mechanically dewatered municipal sewage sludge. The contents of water and ash are high. Also the contents of sulphur and chlorine are higher than those of the wood. The ratio of wood pellets and waste wood was around 50-50. The small deviations from this ratio, seen in Table 1, have no practical importance as these two fuels are quite similar, although some differences in the concentrations of sodium and iron should be noted. At least from a combustion point of view they can be regarded as one fuel. The mixture ratio of these two fuels is important for the heat balance of the furnace, but it does not otherwise significantly affect the results presented here.

The boiler used for the tests is the $12 \mathrm{MW}_{\text {th }}$ CFB boiler at Chalmers University of Technology. This boiler has been described in some detail by Leckner et al. [7]. The bed temperature was about $850{ }^{\circ} \mathrm{C}$, the excess air ratio 1.2 , and $60 \%$ of the air was supplied from the bottom as primary air, the rest being secondary air. The measurements were carried out in the gas path downstream of the primary cyclone. A deposition tube with a surface temperature of $500{ }^{\circ} \mathrm{C}$, upon which solid deposits were formed, was inserted into the centre of the gas

Table 2

Fuel properties (daf means dry and ash-free)

\begin{tabular}{lccc}
\hline & $\begin{array}{c}\text { Wood } \\
\text { pellets }\end{array}$ & $\begin{array}{c}\text { Waste } \\
\text { wood }\end{array}$ & $\begin{array}{c}\text { Sewage } \\
\text { sludge }\end{array}$ \\
\hline Proximate analysis & & & \\
Moisture (m\%, raw) & 8.7 & 33.1 & 73.2 \\
Ash (m\%, dry) & 0.5 & 0.8 & 47.8 \\
Combustibles (m\%, dry) & 99.5 & 99.2 & 52.2 \\
Volatiles (m\%, daf) & 81.9 & 82.3 & 95.9 \\
Ultimate analysis (m\%, daf) & & & \\
C & 50.4 & 49.8 & 51.7 \\
H & 6.1 & 6.1 & 7.2 \\
O & 43.4 & 43.8 & 32.9 \\
S & 0.01 & 0.01 & 1.8 \\
$\mathrm{~N}$ & 0.09 & 0.23 & 6.2 \\
$\mathrm{Cl}$ & 0.01 & 0.03 & 0.12 \\
Lower heating value (MJ/kg daf) & 18.7 & 18.0 & 19.4 \\
Ash analysis (g/kg dry ash) & & & \\
$\mathrm{K}$ & 87 & 68 & 13 \\
$\mathrm{Na}$ & 8.1 & 25 & 7.8 \\
$\mathrm{Al}$ & 15 & 15 & 73 \\
$\mathrm{Si}$ & 75 & 94 & 130 \\
$\mathrm{Fe}$ & 16 & 110 & 170 \\
$\mathrm{Ca}$ & 180 & 130 & 42 \\
$\mathrm{Mg}$ & 33 & 22 & 10 \\
$\mathrm{P}$ & 13 & 6.0 & 66 \\
$\mathrm{Zn}$ & 2.8 & 6.5 & 1.5 \\
\hline
\end{tabular}


path at a gas temperature of $825^{\circ} \mathrm{C}$. The tube was exposed between 8 and $12 \mathrm{~h}$ in each case. Downstream of the convective heat exchangers following the deposit tube, at a gas temperature of $270{ }^{\circ} \mathrm{C}$, fly ash particles were sampled isokinetically to be analysed in a DLPI (Dekati Low Pressure Impactor), determining the particle mass-size distribution, and in an ELPI (Electrical Low Pressure Impactor) system, determining the number-size distribution. The composition of the samples was analysed by ICP-OES (Inductive Coupled Plasma-Optical Emission Spectrometry) and ICP-MS (Inductive Coupled Plasma-Mass Spectrometry). The relative concentration of selected critical compounds $\left(\mathrm{KCl}, \mathrm{K}_{2} \mathrm{SO}_{4}\right.$, $\left.\mathrm{K}_{2} \mathrm{CO}_{3}, \mathrm{CaCl}_{2}, \mathrm{NaCl}, \mathrm{Na}_{2} \mathrm{CO}_{3}, \mathrm{Na}_{2} \mathrm{SO}_{4}, \mathrm{Ca}_{3}\left(\mathrm{PO}_{4}\right)_{2}, \mathrm{CaSO}_{4}\right)$ was determined using a TOF-SIMS (Time-of-Flight Second Ion Mass Spectrometer) instrument. This instrument carries out surface analysis (on the atomic layers of the surface of a sample). The ion-gun can also penetrate into the material to analyse a specific point inside the sample ('depth analysis') on amorphous (such as sludge ashes) and non-amorphous materials in contrast to many other methods of analysis (such as X-ray powder diffraction, XRD) that can only analyse nonamorphous materials.

In addition to the particle measurements, the gas concentration was measured at the exit of the primary cyclone and in the stack. Here, concentrations of $\mathrm{SO}_{2}$ from conventional gas analysers and $\mathrm{HCl}$ measured by an FTIR (Fourier Transform Infra Red) analyser will be especially discussed.

\section{Results}

\subsection{Deposits on the tube}

Fig. 1 presents a summary of the initial deposition rate and the composition of the deposits collected on the deposition tube. The bars indicate the species in the entire deposit on the tube, and the circle diagrams give the selected compounds analysed by TOF-SIMS as average values of four spots on the front side (also called wind side) of the tube. Results from three groups of fuels are shown: wood, wood+zinc, and wood+ zinc + chlorine with and without addition of sewage sludge. Without sewage sludge, wood gives the smallest deposit, consisting almost entirely of potassium sulphate (and also of calcium compounds, not analysed for the particular diagram). During addition of $\mathrm{ZnO}$, a corresponding variety of zinc compounds are added to the potassium sulphate, but these are small quantities as seen from the bars, and they are not shown in the circle diagrams. Addition of chlorine to the furnace to represent a fuel with high chlorine content considerably

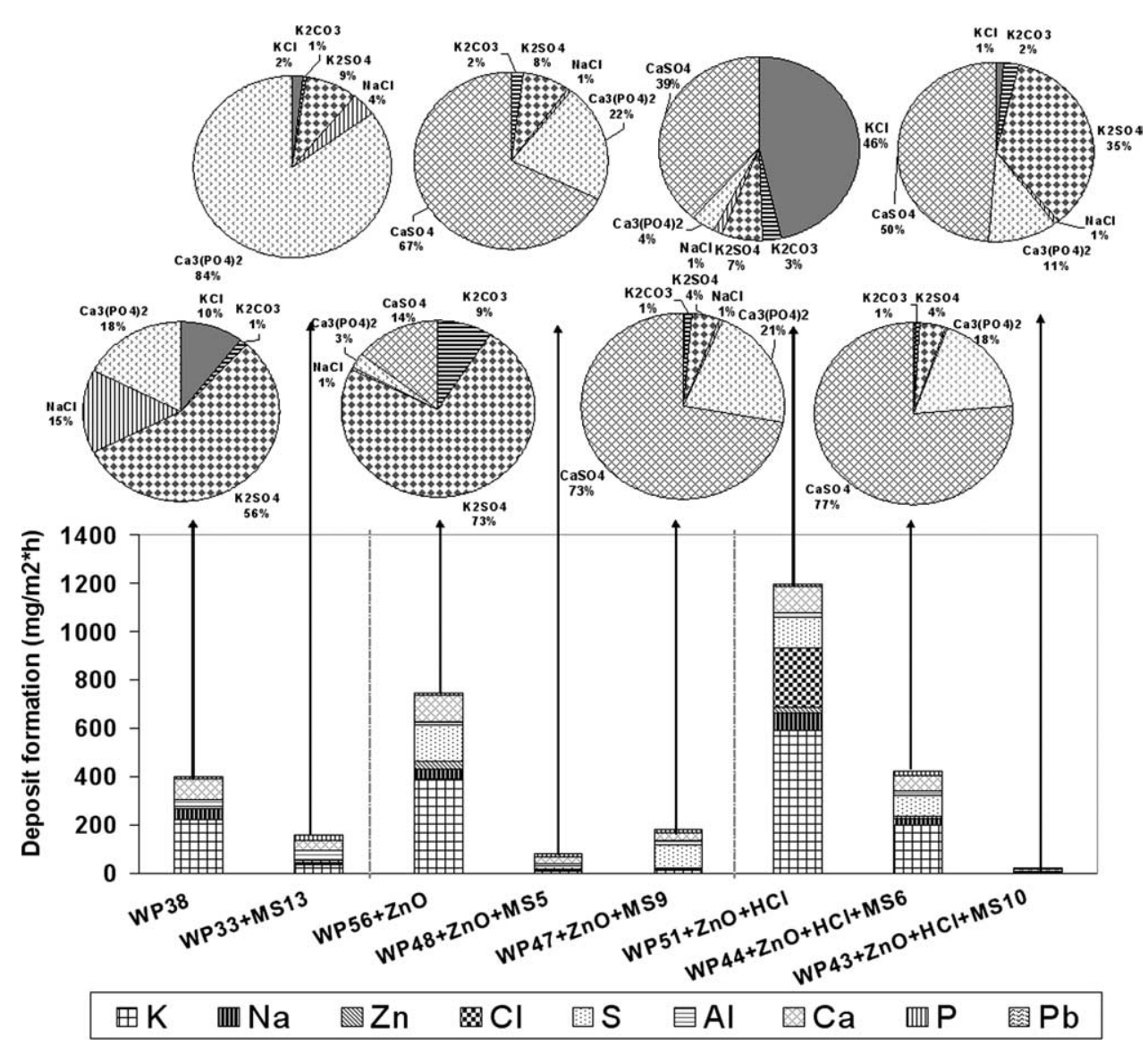

Fig. 1. Rate of deposition on a tube located in the flue gas path at $825^{\circ} \mathrm{C}$. The bars are subdivided into species found in the deposits. The circle diagrams show selected compounds analysed with a TOF-SIMS instrument. In the two first circle diagrams calcium sulphate was not included in the analysis. For the denomination of fuel mixes, see Table 1 . 
enhances the rate of deposition, now dominated by potassium chloride. In all cases, addition of municipal sewage sludge strongly reduced the deposits. From the bar diagram it seems that, predominantly, the potassium compounds are removed during sludge addition, whereas the zinc compounds remain. In all cases calcium plays an important part in the form of $\mathrm{CaSO}_{4}$ and, especially during addition of sludge, $\mathrm{Ca}_{3}\left(\mathrm{PO}_{4}\right)_{2}$. Sodium behaves almost similar to potassium, but there are only small amounts in the deposits in Fig. 1, as well as in the following figures, showing the composition of fly-ash particles.

\subsubsection{Particles}

At the same time as the deposits were collected on the tube, number and mass size-distributions of particles in the gas stream were measured by the ELPI and the DLPI systems in the gas path downstream of the convection tube bundles at a gas temperature of $270{ }^{\circ} \mathrm{C}$.

Fig. 2 shows an example of the number-size distribution of particles in cases with and without sludge addition. The same tendencies were obtained in all cases, but not always as cleancut as in Fig. 2. The number of submicron particles is reduced by addition of sludge, whereas the number of particles in the range above one micron is not so much affected. The same case, now expressing mass-size distributions, is presented in Fig. 3. The total mass sampled, Fig. 3a, shows that the larger number of submicron particles, seen in Fig. 2 in the case without sludge addition, corresponds to a larger mass of particles, and that these particles are removed by the sludge addition. The small change in number size distributions in the super-micron range during sludge addition becomes more visible expressed as particle mass: the particle mass is clearly greater in this range with sludge addition than without. These results are further explained by the accompanying diagrams, Fig. $3 \mathrm{~b}$ and $\mathrm{c}$, expressing the composition of the particle samples. Fig. 3b shows the sum of components containing K, $\mathrm{Na}, \mathrm{Zn}, \mathrm{Cl}, \mathrm{S}$ in each size fraction with and without sludge addition compared with the total mass of particles in a corresponding case without sludge addition. Quite clearly, the

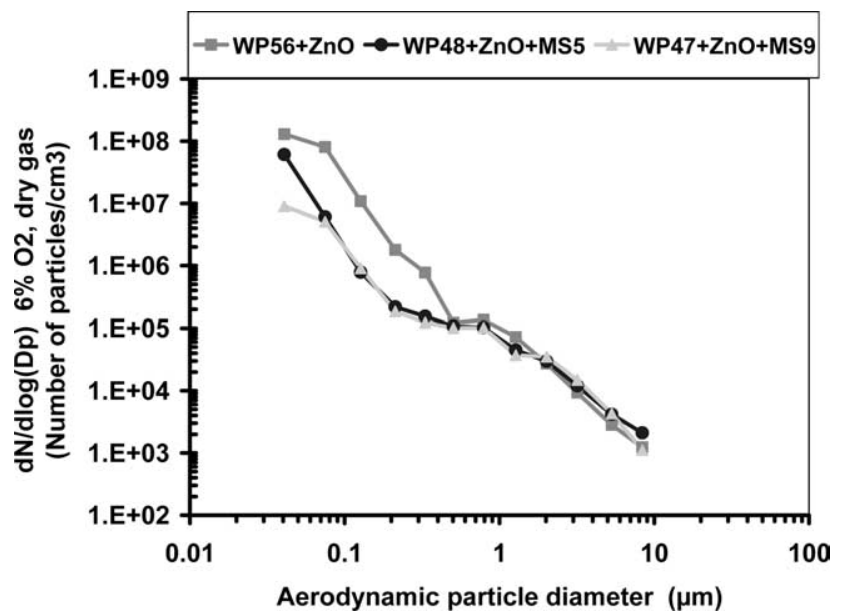

Fig. 2. Example of number size-distribution of particles collected in the flue gas path at $270{ }^{\circ} \mathrm{C}$ with and without sludge addition.
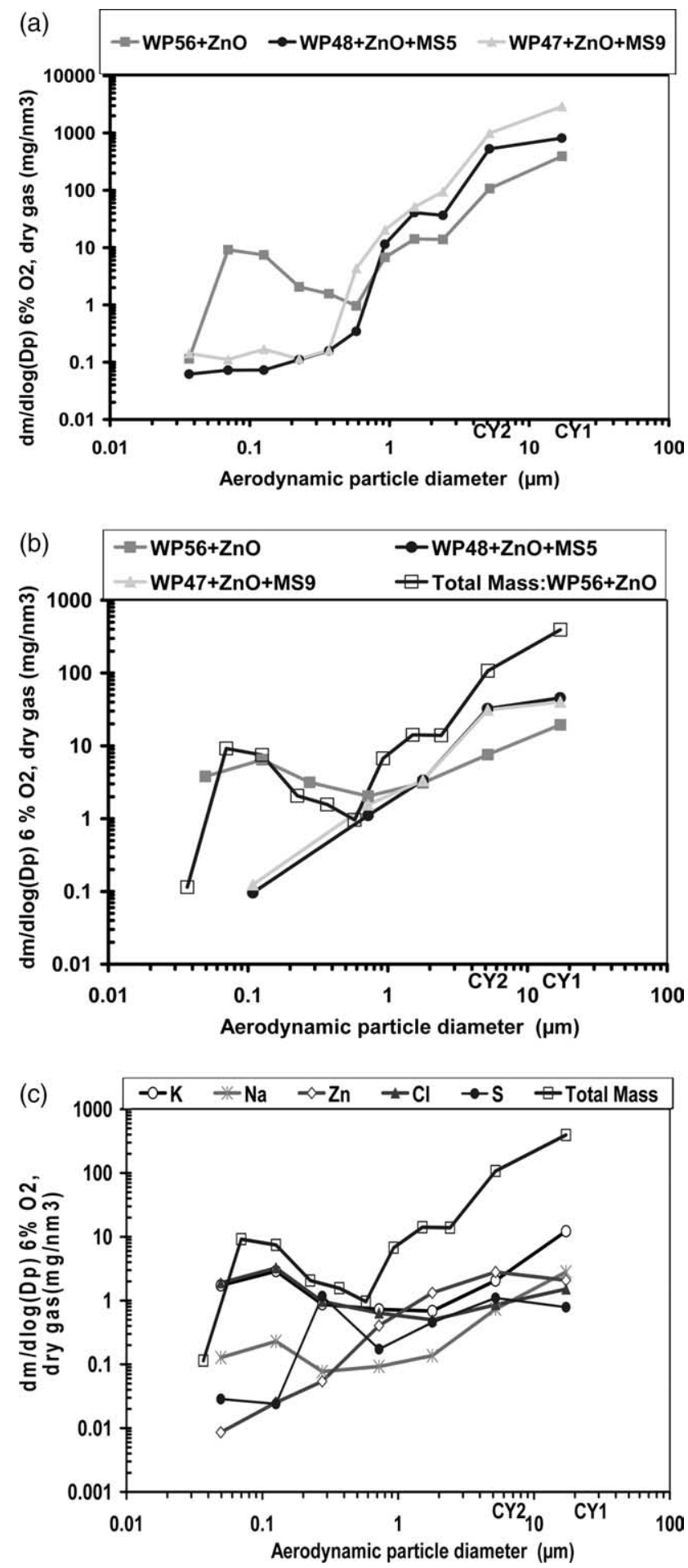

Fig. 3. (a) Mass size-distribution of particles collected in the flue gas path at $270{ }^{\circ} \mathrm{C}$ in the same case as Fig. 2. CY1 and 2 were measured by small cyclones attached to the impactor. (b) The sum of $\mathrm{K}, \mathrm{Na}, \mathrm{Zn}, \mathrm{Cl}$ and $\mathrm{S}$ from the cases in (a) compared with the total mass collected in the case WP56+ $\mathrm{ZnO}$ for various particle sizes. (c) Total mass collected in WP56 $+\mathrm{ZnO}$ compared with the species summarized in (b) for various particle sizes.

alkali compounds are predominantly removed by sludge addition in the submicron range, whereas they rise in mass in the super-micron range. In this range there is also a considerable contribution of other species, as illustrated by 
the gap between the curves representing the sum of the selected species and the total amount of particles. These relationships are further clarified by Fig. 3c, showing that $\mathrm{KCl}$ contributes mostly to the submicron peak in the particle size distribution of the fly-ash particles in contrast to the size-integrated deposit on the tube that consists of $\mathrm{K}_{2} \mathrm{SO}_{4}$ to a large extent. Sulphur is found in a low concentration in the small particle range of Fig. 3c, except at $0.3 \mu \mathrm{m}$, where it is similar to those of $\mathrm{K}$ and Cl. Fig. 3c also indicates that the amount of zinc is small, especially in the submicron range.

Fig. 4a shows selected compounds from the sum of $\mathrm{K}, \mathrm{Na}, \mathrm{Zn}$, $\mathrm{Cl}$ and $\mathrm{S}$ in Fig. 3b compared to the corresponding tests with $\mathrm{HCl}$ addition, Fig. 4b. The circle diagrams represent the sum of $\mathrm{Ca}, \mathrm{K}$, $\mathrm{Na} \mathrm{Cl}$, and $\mathrm{S}$ compounds also shown by the corresponding solid curves in each diagram. Just like in the deposits on tubes, Fig. 1, $\mathrm{CaSO}_{4}$ is an important fly ash constituent in all cases, mostly above $1 \mu \mathrm{m} . \mathrm{KCl}$ is found in all samples, but only in small quantities where sludge is added. Especially in the sludge cases, phosphorous appears in the form of $\mathrm{Ca}_{3}\left(\mathrm{PO}_{4}\right)_{2}$. From a comparison between Fig. $4 \mathrm{a}$ and $\mathrm{b}$, it is clear that the mass of particles containing $\mathrm{Ca}, \mathrm{K}, \mathrm{Na}, \mathrm{Zn}, \mathrm{Cl}$ and $\mathrm{S}$ increases considerably in the submicron range during addition of $\mathrm{HCl}$.

The conclusions from the TOF-SIMS measurements, shown in the circle diagrams, concern only the specified compounds. In the size distributions of total mass, compounds containing aluminium, silicon, iron and other possible components are also included. In order to give an impression of the mass composition of the main elements in the ash particles collected by the DLPI, an overview is shown in Fig. 5. The data in this figure are normalised so that the amount captured in each step of the impactor becomes $100 \%$. The gap between the curves in the diagrams and $100 \%$ are trace elements. It is clear that in the

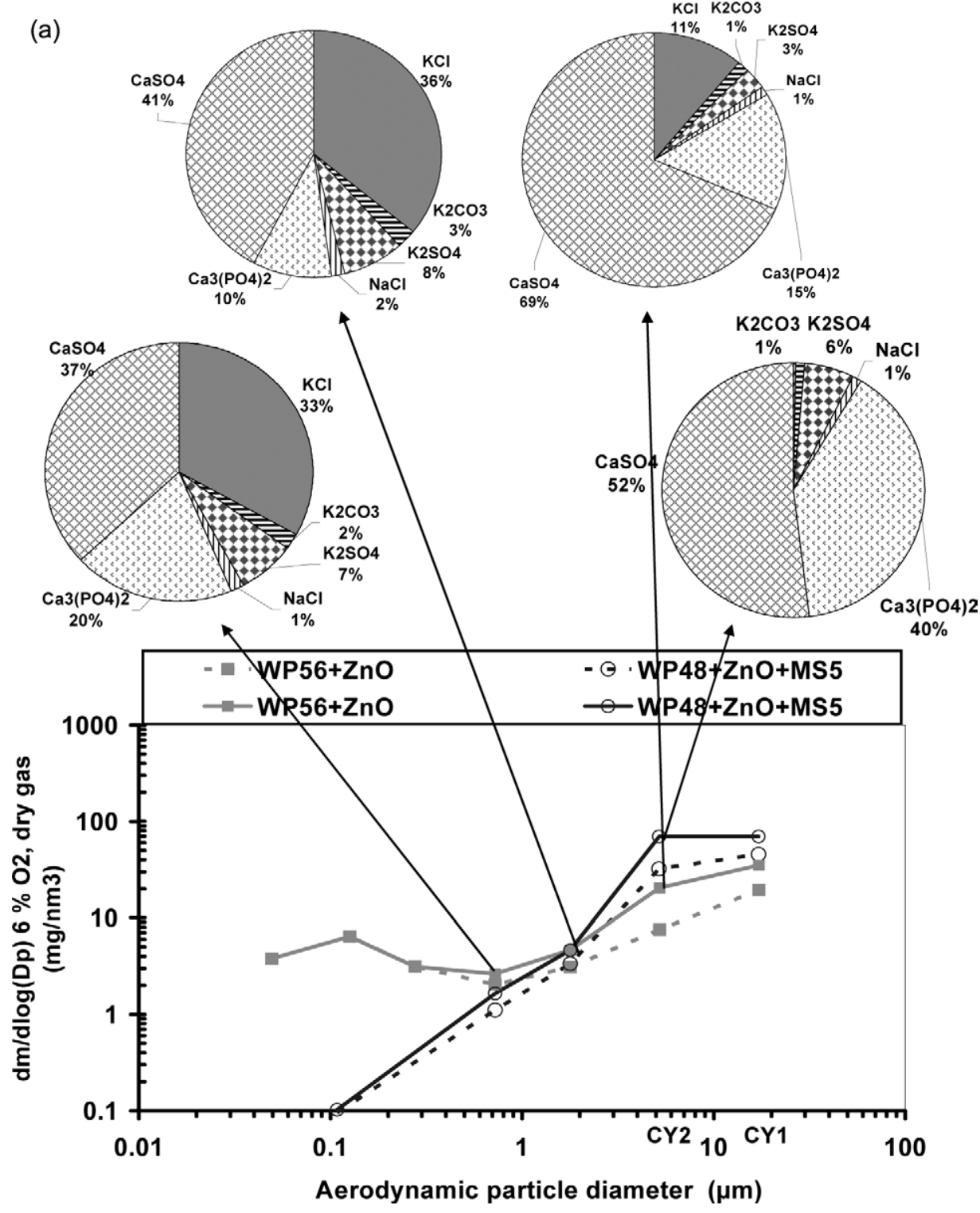

Fig. 4. Comparison between compositions in cases with and without sludge and without (a) and with (b) chlorine addition for various particle sizes. Dashed line is sum of $\mathrm{K}, \mathrm{Na}, \mathrm{Zn}, \mathrm{Cl}$ and $\mathrm{S}$. Full line is sum of $\mathrm{Ca}, \mathrm{K}, \mathrm{Na}, \mathrm{Cl}$, and $\mathrm{S}$. Compounds of the solid lines are analyzed with the TOF-SIMS and shown in the circle diagrams. 


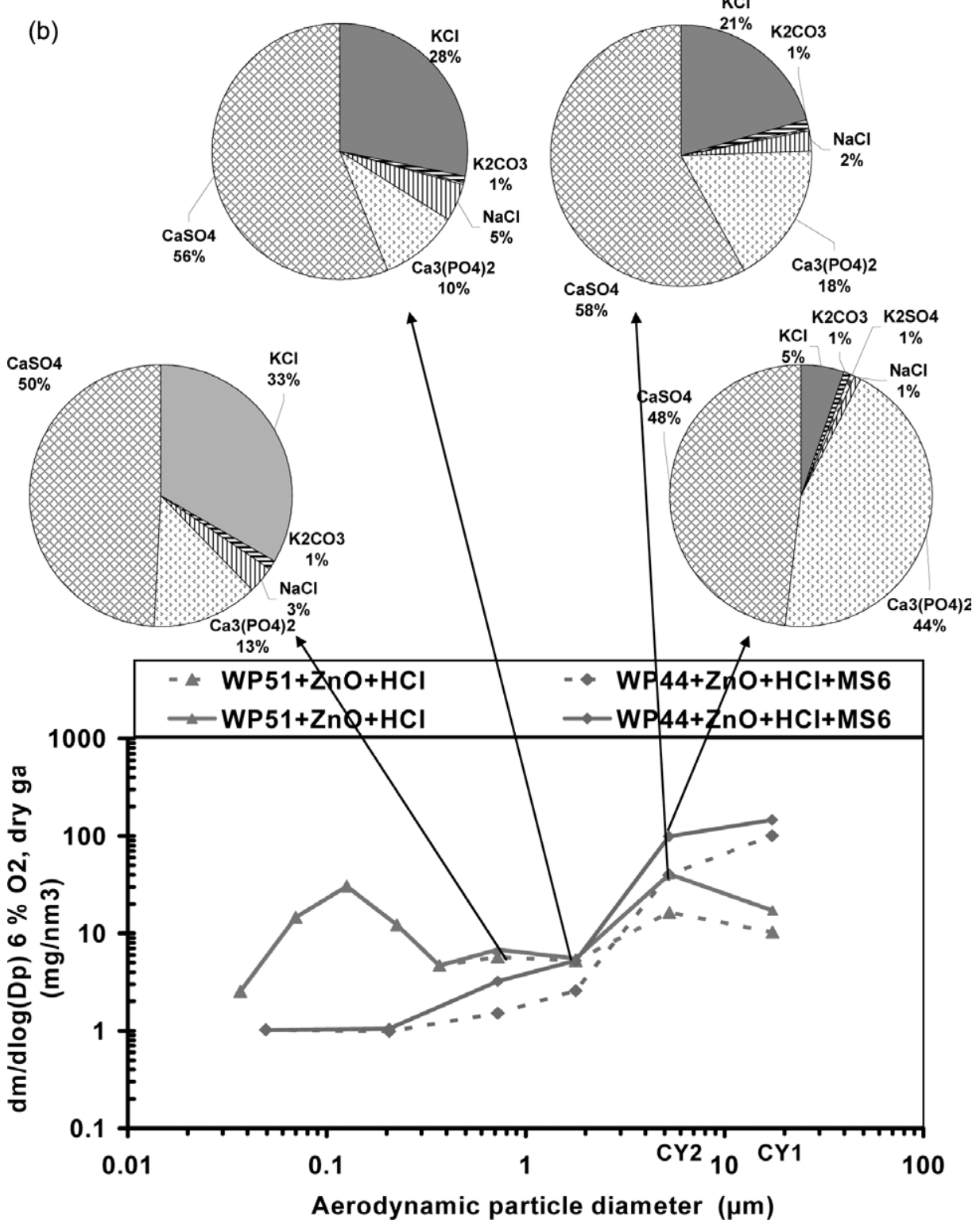

Fig. 4 (continued)

small particle range of the diagrams without sludge addition, $\mathrm{K}$ and $\mathrm{Cl}$ dominate. Sulphur forms a narrow band in agreement with Fig. 3c. Al, Si and Fe are found predominantly towards the large size end of the diagrams. Zinc also forms a relatively narrow band, especially visible during zinc addition. During addition of sludge, potassium and chlorine almost disappear from the low size range except in two cases, MS5 and MS6. The amount of sludge in these cases is about half of that of the other cases and the most likely explanation is that this is an effect of the amount of sludge added; the sludge addition was still not sufficient to remove all $\mathrm{KCl}$. Otherwise, the diagrams with sludge addition reflect some well known constituents of municipal sewage sludge: phosphorus, and iron from the flocculation agent.

The concentrations of $\mathrm{HCl}$ and $\mathrm{SO}_{2}$ may give some complementary information. These concentrations, measured at the exit of the primary cyclone (where the deposition tube was located) and at the stack, are shown in Fig. 6, compared with the corresponding emissions if the content of chlorine and sulphur in the fuel were converted into $\mathrm{HCl}$ and $\mathrm{SO}_{2}$ ('theoretical' values). The results are not perfectly consistent (the case WP38 differs) but some tentative observations can be tried: both $\mathrm{SO}_{2}$ and $\mathrm{HCl}$ are removed from the gas by the alkali to a larger extent when sludge is not added than when sludge is present. When sludge is present there is hardly any sulphur removal at all, despite excess $\mathrm{Ca}+\mathrm{K}_{2}+\mathrm{Na}_{2}$ in all cases.

\section{Discussion}

The addition of sludge had a clear effect: the formation rate of deposits was reduced and the submicron particles, 

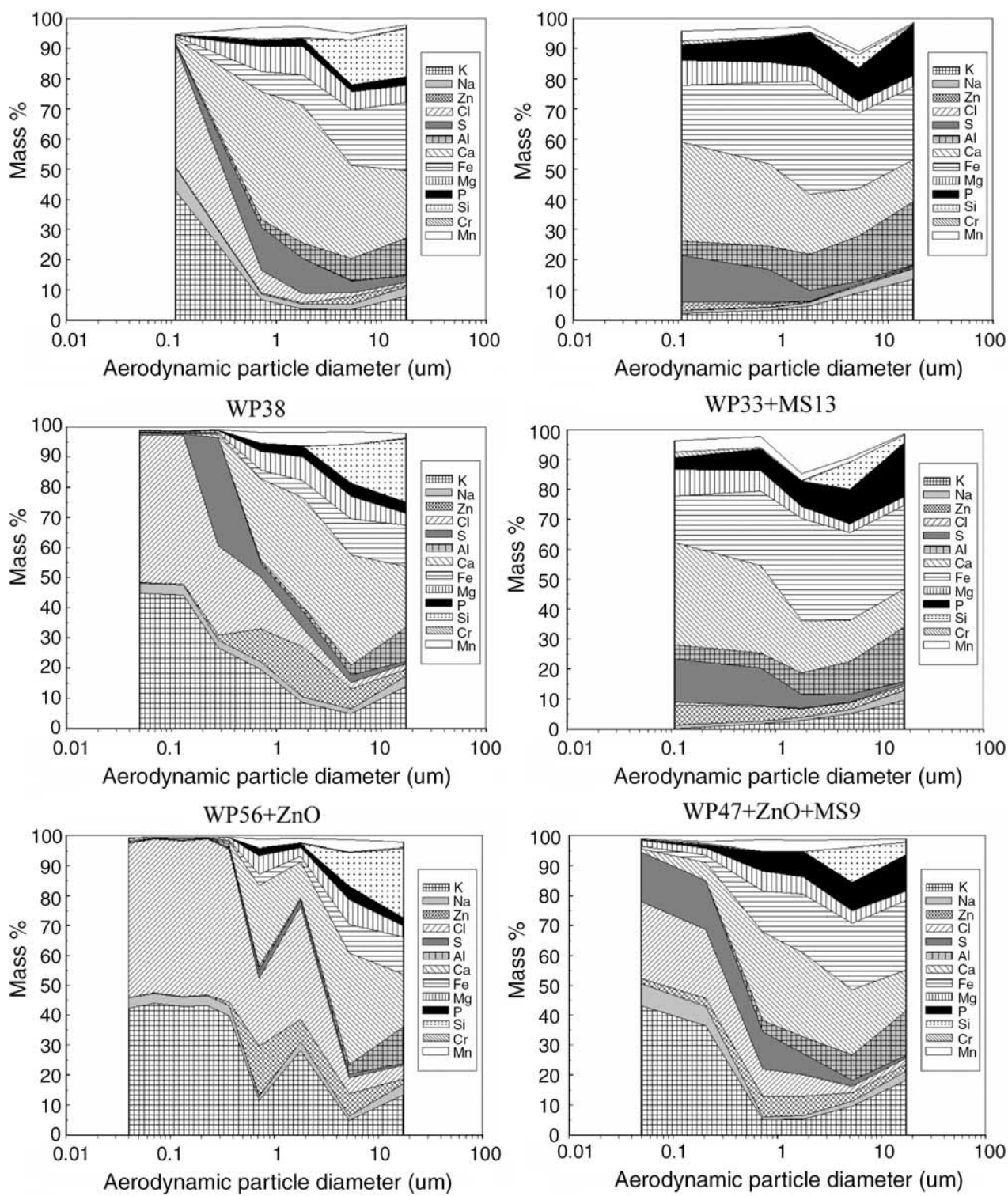

$\mathrm{WP} 51+\mathrm{ZnO}+\mathrm{HCl}$
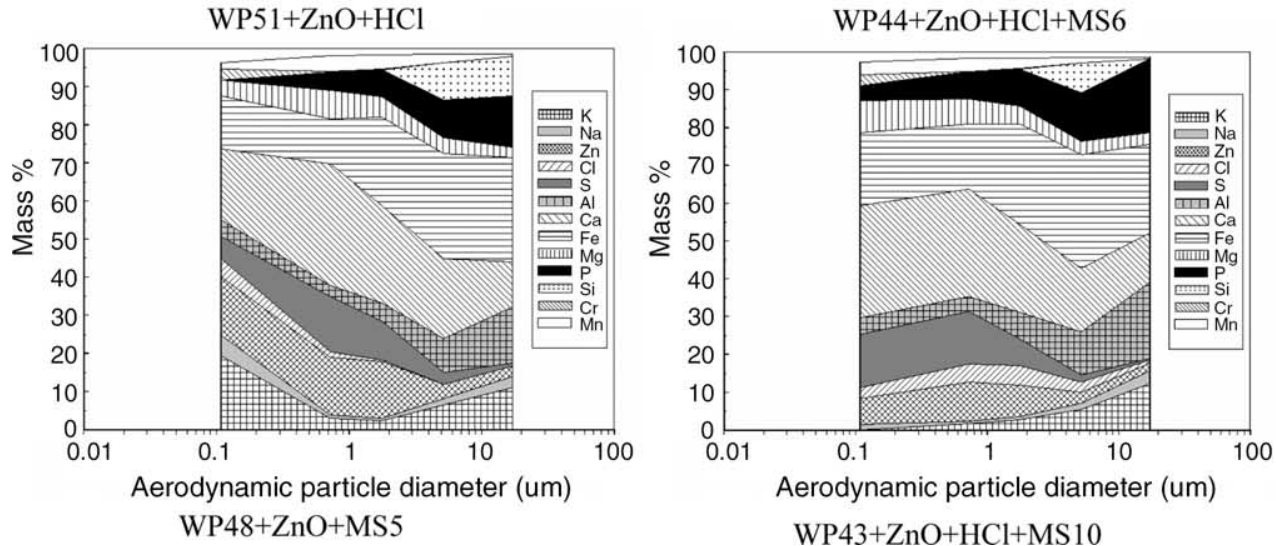

Fig. 5. Composition of particle size distributions in the cases investigated.

predominantly consisting of $\mathrm{KCl}$, almost disappeared. There are, at least, four explanations to be discussed regarding reduction of the rate of formation of solid deposits on tubes during addition of sludge. This discussion is probably valid for any other fuel that fulfils the criteria mentioned below.
(I) If sulphur is present, alkali ( $\mathrm{K}$ or $\mathrm{Na}$, denoted $\mathrm{M}$ ) chloride, released during the fuel conversion process, can be transformed into a sulphate through the overall reaction

$$
2 \mathrm{MCl}+\mathrm{SO}_{2}+1 / 2 \mathrm{O}_{2}+\mathrm{H}_{2} \mathrm{O} \Rightarrow \mathrm{M}_{2} \mathrm{SO}_{4}+2 \mathrm{HCl}
$$



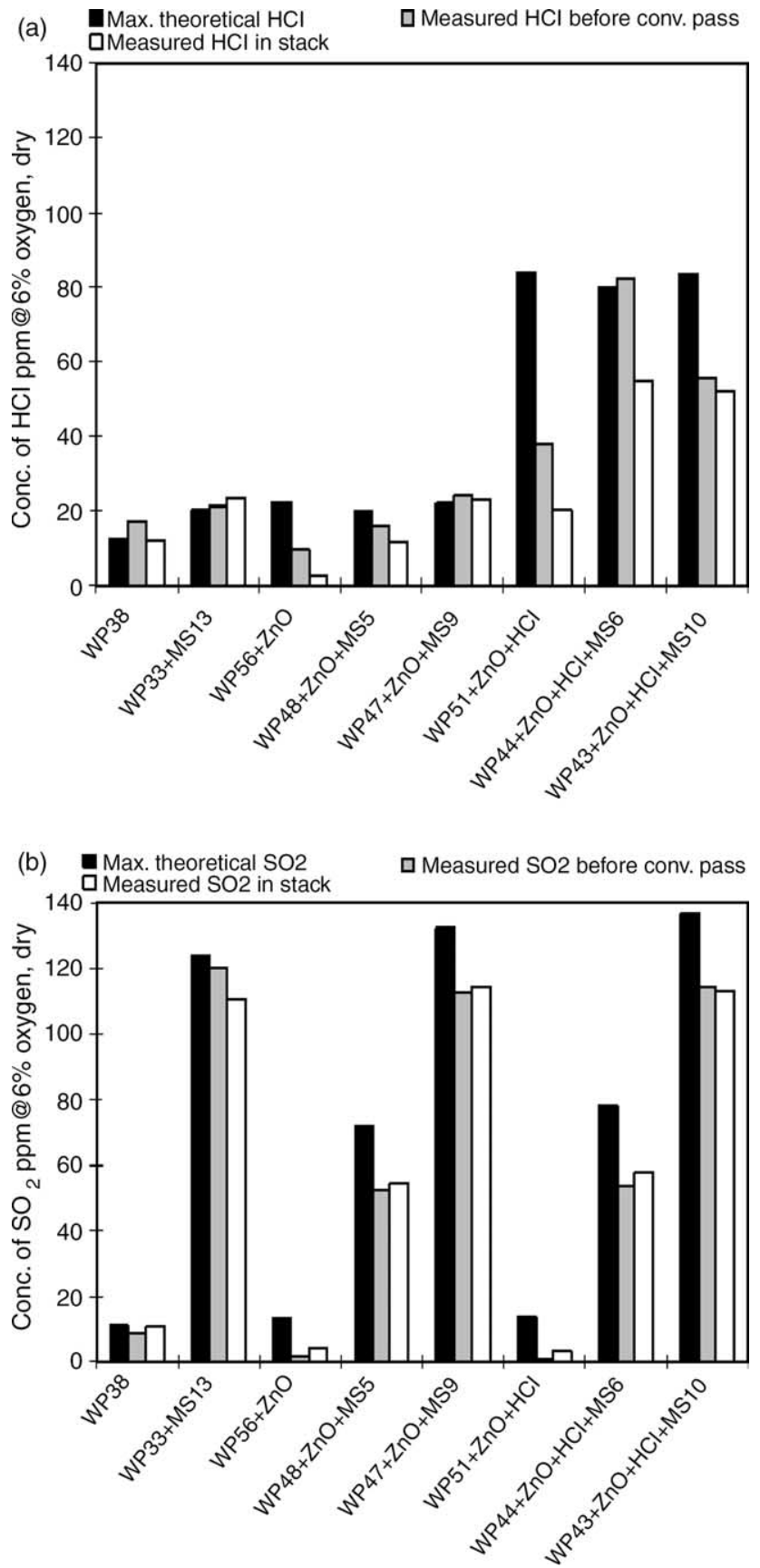

Fig. 6. Gas concentrations (a) $\mathrm{HCl}$, (b) $\mathrm{SO}_{2}$.

Then, less deleterious deposits containing sulphate will be formed. The formation of deposits will also decrease, since $\mathrm{K}_{2} \mathrm{SO}_{4}$ is likely to be solid in the gas and less inclined to stick to the tube surfaces. It has been proposed by Krause [8] that when the molar ratio of $\mathrm{S} / \mathrm{Cl}$ in the fuel is greater than 4 , corrosion caused by chlorine will be negligible. Similarly, it was stated by Robinson et al. [4] that when the molar ratio $2 \mathrm{~S} /(\mathrm{K}+\mathrm{Na})>4$, the $\mathrm{Cl}$ content in deposits is negligible. The term $(\mathrm{K}+\mathrm{Na})$ expresses the amount of 'available' alkali in the mineral part of the fuel, hence excluding alkali firmly bound in minerals. It is well known that this is a simplified concept, and that several complications have to be considered when relating these ratios to deposits [1,2]. Leaching tests show that alkali in wood is almost entirely free to be released [1] (it is available), whereas alkali in sludge is likely to be bound to a great extent in the ashes. This means that, in the sludge cases, the $2 \mathrm{~S} /(\mathrm{K}+\mathrm{Na})$ ratio given in Table 1 is increased to higher values than those given in the table, and then the criteria are fulfilled as long as the sulphur is not removed by some additional sorbent like lime. This is, however, what took place in the cases without sludge. On the one hand, sulphur is captured by calcium originating from the fuel (no calcium was added) as seen in all diagrams, and, hence, the sulphur content in the ratios given should be reduced. On the other hand, the phosphorus, introduced especially with sludge, reacts with calcium, thereby preventing sulphur capture, Amand and Leckner [9], making the sulphur available for other reactions. This is a likely explanation to the low overall sulphur capture reflected by the data in Fig. 6. The situation is complex and has to be further treated in order to make quantitative predictions.

(II) When sludge is added, the particle concentration in the gas increases. $\mathrm{KCl}$, condensing during cooling of the gas in the convection path, as is clearly noted from the submicron particles without sludge addition in Figs. 2 and 3, could be captured by the sludge ash, serving as a surface for condensation (heterogeneous condensation, [6]). Such a possibility has been mentioned by Valmari [10] and Lind [4], who also observed tendencies of condensation of alkali chlorides on coarser particles in the fly ash in a flue gas path similar to the present one (see Fig. 4 in [4]). They pointed out that some condensation also could take place on submicron particles.

(III) The third possibility is a chemical reaction between the components of the sludge ash, particularly alumino-silicates, and potassium, liberating chlorine in gaseous form $(\mathrm{HCl})$ and binding the potassium in the ashes according to the overall reaction

$$
\begin{gathered}
\mathrm{Al}_{2} \mathrm{O}_{3} \cdot 2 \mathrm{SiO}_{2(\mathrm{~s})}+2 \mathrm{MCl}_{(\mathrm{g})}+\mathrm{H}_{2} \mathrm{O}_{(\mathrm{g})} \\
\Rightarrow \mathrm{M}_{2} \mathrm{OAl}_{2} \mathrm{O}_{3} \cdot 2 \mathrm{SiO}_{2(\mathrm{~s})}+2 \mathrm{HCl}_{(\mathrm{g})}
\end{gathered}
$$

Since the effect of sludge addition is shown as a reduction of the amount of deposit on the deposition tube, it is likely that the transformations have taken place already in the furnace, while potassium is in gas phase. The reactions between sodium (which is quite similar to potassium) and kaolinite was shown to be faster for $\mathrm{NaOH}$ than for $\mathrm{NaCl}$, Mwabe and Wendt [11], whereas Tran et al. [12] did not find any difference in reaction rate for $\mathrm{KOH}$ and $\mathrm{KCl}$ and kaolin under combustion conditions ( $850{ }^{\circ} \mathrm{C}$ and water vapour present). In the present case, any of the potassium compounds mentioned could have been present initially and reacted with alumino-silicates even before $\mathrm{K}_{2} \mathrm{SO}_{4}$ was formed (this deposit also disappeared). Here it is sufficient to state that this is a likely process, enhanced by the increased ash flow during addition of sludge. The small effect on $\mathrm{HCl}$ emission during addition of sewage sludge also points in this direction (Reaction 2). A suggestion that alumino-silicates are 
important for binding potassium from biomass combustion has been made by Aho $[2,13,14]$ in connection to co-combustion of coal and other fuels. Aho and Silvennoinen [13] suggested that a molar ratio of reactive $(\mathrm{Al}+\mathrm{Si}) /($ fuel $\mathrm{Cl})$ higher than $8-10$ was needed to prevent chlorine in deposits.

(IV) Finally, there is a possibility that remains to be investigated, namely, that the increased ash flow during addition of sludge has a scavenging effect, eroding the deposits building up. Such a mechanism has been suggested in other contexts by Ots [15]. Erosion by impingement of solid ash particles should be most notable on the wind side of the tube, leaving the rear side unaffected. The present tests were not operated long enough, though, to further study the possible impact of such an effect, but removal of deposits of $\mathrm{KCl}$ by abrasion is known to be difficult. Furthermore, the observed absence of small $\mathrm{KCl}$ particles in the gas during sludge addition points to other mechanisms as being more likely.

The present data do not allow a clear differentiation between the modes of disappearance of deposits. The results, supported by the references quoted, permit some indications, however. When the $\mathrm{S} / \mathrm{Cl}$ ratio is sufficiently high, sulphates dominate and deposits of $\mathrm{KCl}$ are absent. When the $\mathrm{S} / \mathrm{Cl}$ ratio is low $\mathrm{KCl}$ dominates. Hence, there was an effect of sulphur/chlorine ratio. When sludge is added, it is clear that the condensate products carrying $\mathrm{KCl}$ are removed. It is likely that the removal of $\mathrm{KCl}$ and other alkali compounds takes place in the furnace upstream of the deposition tube, hence by Mechanism III, which leads to reduction of the deposition rate. As shown in Fig. 5, very little chlorine and sulphur are present in the larger size particles. Instead, aluminium and silicon are found there together with potassium. This fact also points at a dominant role of the third option and not of the second one. Also, the molar ratio $(\mathrm{Al}+$ $\mathrm{Si}) /(\mathrm{Na}+\mathrm{K})$ is high (Table 1) when sludge is added, although it is not known if the $\mathrm{Al}+\mathrm{Si}$ species in sludge are in the form of reactive alumino-silicates. It is known, however, that in the order of $10 \%$ of the dry substance of sludge consists of zeolites [16] and this, again, supports Mechanism III. The first and the second options could have contributed to some extent, but not enough to show clear traces of chlorine in the particles captured. Another option, implying that particles, captured by other particles during condensation of $\mathrm{KCl}$, would react after having been captured, can be considered less probable, because of the solid-solid reaction condition and the falling temperature (slow reactions) as the gases proceed in the flue gas path.

The investigation was carried out in the flue gas path whose conditions are quite independent of combustor type. The question, whether the combustor type could have some importance for the results, was not explicitly studied. However, for co-combustion of the types of fuels considered, fluidized bed is probably much more useful than grate firing, and flame combustion does not seem to be practical at all. The temperature level, where the release of volatiles that takes place in a fixed and fluidized bed is in the same range in both types of bed, and the volatilized inorganic compounds should be similar. The principal difference between the combustion devices could be chemical interaction between bed material and the inorganic gases. The gases can react with the bed material, be retained in the bed and, hence, more or less be removed from the flue gases. This takes place already to some extent with common bed materials, such as silica sand [17], but could be conducted to an extreme degree, namely by using kaolin mixed with the bed [18]. On the other hand some bed materials, like olivine sand or blast furnace slag (Brus et al., [19]), would not react significantly with alkali, and hence, they would permit the alkali to follow the flue gas. These features of bed material support Mechanism III, and the conclusion is that the best possible contact arrangement for chemical reaction (bed operation conditions) to capture alkali compounds by bed material should be used. This aspect remains to be studied more in detail.

\section{Conclusion}

Deposits on heat transfer tubes from biomass fuels are radically reduced by co-firing, even with relatively small amounts of sewage sludge. Although it was not investigated here, this statement can probably be generalised to any biomass fuel containing free alkali and to any co-fired fuel, containing sulphur and alumino-silicates in their ashes. The results were derived from measurements in the flue-gas path of a circulating fluidized bed boiler, which is the most suitable combustion device for the types of fuels concerned.

Four mechanisms can be active to remove the most common undesirable deposit, potassium chloride: reaction between potassium chloride and sulphur when there is an excess of sulphur, heterogeneous condensation on ash particles, reaction with alumino-silicates, and abrasion of the deposit by the enhanced ash flow. Among these options the first and the third are deemed to be the most important ones. Even though the $\mathrm{S} / \mathrm{Cl}$ ratio is high during sludge addition, in the larger particle range the potassium concentration increases together with those of aluminium and silicon, whereas sulphur and chlorine concentrations are low. This supports Mechanism III, removal by reaction between alkali and alumino-silicates.

\section{Acknowledgements}

This work was supported financially by the Swedish National Energy Administration. Operation of the boiler by personnel from Akademiska Hus, support in sampling and recollection of data from the technical staff of Division of Energy Conversion, and the patient support in carrying out chemical analyses of the particle samples and deposits by Peter Sjövall and Benny Lyvén at the Swedish Testing and Research Institute are gratefully acknowledged.

\section{References}

[1] Yrjas P, Skrifvars B-J, Hupa M, Roppo J, Nylund M. Vainikka P. Chlorine in deposits during co-firing of biomass, peat, and coal in a full-scale 
CFBC boiler. In: Proceedings of FBC2005, the 18th international conference on fluidized bed combustion. Toronto: American Society of Mechanical Engineers, 2005. Paper FBC2005-78097.

[2] Silvennoinen J, Roppo J, Nurminen R-V, Aho M, Vainikka P, Ferrer E. Co-combustion of coal with RDF and biomass- prevention of chlorine deposition by using coal ash alkali absorption ability. Proceedings of FBC2005, the 18th international conference on fluidized bed combustion. Toronto: American Society of Mechanical Engineers, 2005. Paper FBC2005-78120.

[3] Robinson AL, Junker H, Baxter LL. Pilot scale investigation of the influence of coal-biomass cofiring on ash deposition. Energy Fuels 2002; 16:343-55.

[4] Lind T, Valmari T, Kauppinen E, Nilsson K, Sfiris G, Maenhaut W. Ash formation mechanisms during combustion of wood in circulating fluidized beds. Proceedings of the 28th symposium (international) on combustion. Pittsburgh: The Combustion Institute; 2000. p. 2287-95.

[5] Åmand L-E, Leckner B, Eskilsson D, Tullin C. Deposition on heat transfer tubes during combustion of demolition wood. Energy and Fuels (accepted).

[6] Sarofim AF, Helble JJ. The impact of ash deposition on coal fired plants. In: Williamsom J, Wigley F, editors. Washington: Taylor \& Francis; 1993. p. 567-82.

[7] Leckner B, Åmand L-E, Luecke K, Werther J. Gaseous emissions from co-combustion of sewage sludge and coal/wood in a fluidized bed. Fuel 2004;83:477-86.

[8] Krause HH. High-temperature corrosion problems in waste incineration systems. J Mater Energy Syst 1986;7:322-32.

[9] Åmand L-E, Leckner B. Reduction of emissions of sulphur and chlorine from combustion of high volatile waste fuels (sludge) in fluidised bed. In: Cen K, Yan J, Chi Y, editors. Proceedings of third international conference on combustion, incineration/pyrolysis and emission control,
October 21-23. Hangzhou, China: International Academic Publishers/World Publishing Corporation; 2004. p. 476-81.

[10] Valmari T, Lind TM, Kauppinen EI. Field study on ash behaviour during circulating fluidized-bed combustion of biomass. 2. Ash deposition and alkali vapor condensation. Energy Fuel 1999;13:390-5.

[11] Mwabe PO, Wendt JOL. Mechanisms governing trace sodium capture by kaolinite in a downflow combustor. In: Proceedings of the 26th symposium (international) on combustion. Pittsburgh: The Combustion Institute; 1996, p. 2447-453.

[12] Tran K-Q, Iisa K, Steenari B-M, Lindquist O. A kinetic study of gaseous alkali capture by kaolin in the fixed bed reactor equipped with an alkali detector. Fuel 2005;84:169-75.

[13] Aho M, Silvennoinen J. Preventing chlorine deposition on heat transfer surfaces with aluminium-silicon rich biomass residue and additive. Fuel 2005;83:1299-305.

[14] Aho M, Ferrer E. Importance of coal ash composition in protecting the boiler against chlorine deposition during combustion of chlorine-rich biomass. Fuel 2005;84:201-12.

[15] Ots A. Mechanism of ash deposit formation, corrosion and sulfur capture by burning calcium and chlorine containing fuels. VGB Power Tech 2001;81(10):114-20.

[16] Kurzendörfer CP, Kuhm P, Steber J. Zeolites in the environment. In: Schwuger MJ, editor. Detergents in the environment. New York: Marcel Decker; 1997. p. 127-93.

[17] Nuutinen LH, Tiainen MS, Virtanen ME, Laitinen RS. Coatings layers on bed particles during biomass fuel combustion in fluidized-bed boilers. Energy Fuels 2004;18:127-39.

[18] Öhman M, Nordin A. The role of kaolin in prevention of bed agglomeration during fluidized bed combustion of biomass fuels. Energy Fuels 2000;14:618-24.

[19] Brus E, Öhman M, Nordin A, Boström D, Hedman H, Eklund A. Bed agglomeration chacteristics of biomass fuels using blast-furnace slag as bed material. Energy Fuels 2004;18:1187-93. 